\title{
Student Assessment System for Distance Education on Financial Management
}

\author{
https://doi.org/10.3991/ijet.v11i10.6265 \\ Ying $\mathrm{Yu}$ \\ Changsha Environmental Protection College, Changsha, China
}

\begin{abstract}
This study designs and develops a student assessment system based on the browser/server architecture using the core technology of ASP.NET, supplemented by SQL Server 2005 and Microsoft Visual Studio 2008. The system can be used for online testing of distance education on financial management in colleges and universities. In practical teaching assessment, the system includes an experience mode, a friend-shared learning mode, and a direct test mode; provides users with multiple rounds of experiential, collaborative, and simulative academic testing environments; achieves timely updates of assessment indicators; offers online analysis to teachers and students on test sites; and ultimately achieves a 0 error rate of test papers. In the comparative teaching experiment, the system can greatly enhance the quality of education on financial management and is worthy to be used extensively in teaching.
\end{abstract}

Index Terms-Student assessment system, financial management, distance education, $B / S$ architecture, ASP.NET

\section{INTRODUCTION}

A student academic assessment system is a computer system applied to test the academic level of students online. The system is constructed on the basis of the use of information technology, combines course teaching contents, examination questions, assessment modes, and other contents, and provides informative test management for teaching assessment [1]. Although student academic assessment systems have impressive advancement and test advantages, they have also caused widespread concern in the education sector at home and abroad. For example, in 2013, Kaklauskas et al. developed a student assessment system for distance education by applying biometric voice analysis technologies, self-assessment, intelligence quotient tests, and other methodologies. The Biometric and Intelligent Student Progress Assessment System was designed according to the 13-year experience of the authors in distance learning to conduct psychological assessment of student progress [2]. Several researchers (2013) worked together with their colleagues and created a system for biological and intelligent self-assessment of student progress (bisasp). The function of student selfassessment and teacher assessment of the system enables the user to grasp the learning situation of students even without reference from examinations. The corresponding experimental results verified that the assessment result of the system is similar to that of other assessment research [3]. Yu (2015) examined a comprehensive college student assessment system based on the model-view-controller architecture, which implements assessment content customization, dynamic grade point calculation, and other functions [4]. Zhang (2011) investigated the application of a mental assessment system in the course of academic and career planning of college students and offered a detailed description of the scheme for developing the system [5].

With the rapid development of computer application and Internet technology, online education, as a new way of learning, has been gradually accepted by people. In particular, an online assessment system is an indispensable and important part of the process of online education [6]. Assessment enables those who are assessed to quickly understand their own mastery of what they have learned and helps them achieve self-test, self-diagnosis, and self-learning to stimulate their enthusiasm and thereby further improve the teaching quality. However, the online assessment systems currently available design separate questions based on a certain knowledge point, thus resulting in isolation among the assessment questions, and providing systematic analysis and demonstration of mastery of concepts and knowledge actually included in the test results is difficult [7]. No unified authority for assessment also exists, and some people just conduct the assessment in class or school [8]. Moreover, the content of the assessment is not updated at any time according to the learning progress; this condition undoubtedly affects the accuracy of learning assessment results. In this case, making a systematic analysis of the root causes of the poor mastery of knowledge or further understanding which knowledge points should be strengthened and learned by those who are assessed is impossible [9].

This study is innovative in the following aspects. First, the learning assessment system is synchronous with teaching textbooks, provides unit and comprehensive assessment examination papers designed by top outstanding and specially advanced teachers in the major, and organizes participation from a wide range of users online. Items of assessment are updated according to the learning progress, so that the system can give timely feedback with detailed and comprehensive assessment results and offer the correct resolution processes. In accordance with the statistical data of the actual assessment results, teachers can demonstrate feedback of the assessment results for teaching content in each unit of various disciplines and guide students to preview and review in a timely manner. Therefore, computer technology is employed in this study to develop and apply an academic assessment system based on ASP.NET in the course of financial management. The highly advanced system can realize online testing of the course, selfadaptive management, and other functions.

\section{AnAlysis Of The StUdent Assessment System}

\section{A. Analysis of the Requirements}

The academic assessment system is constructed on the basis of the browser/server $(\mathrm{B} / \mathrm{S})$ architecture, with focus 


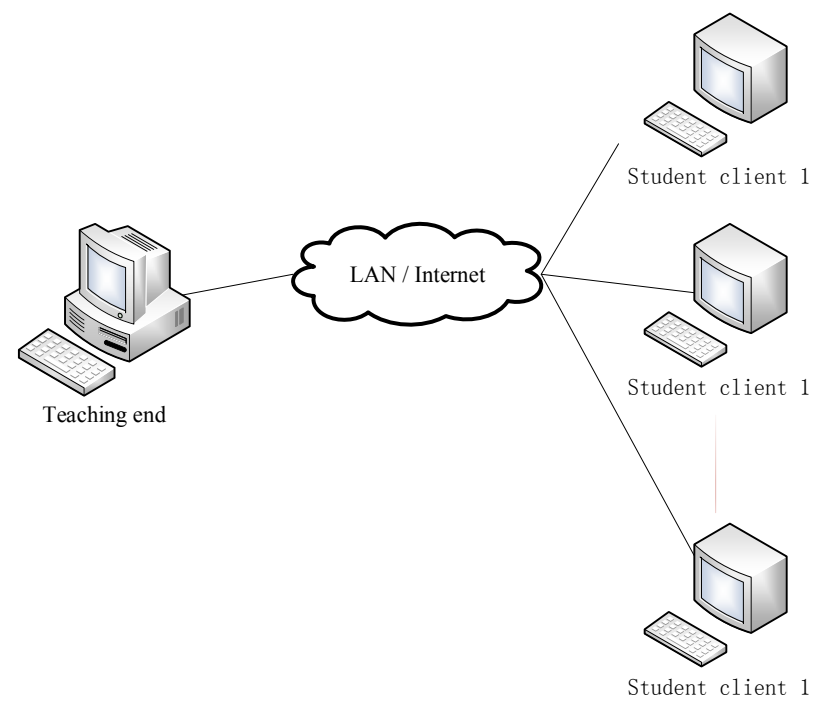

Figure 1. Structural chart of the system

on assessing the teaching of financial management. This system needs to implement online testing, online assessment, system setting, and other functions. These functional requirements mainly aim to complete online testing of the course automatically through a computer. Operations of the system primarily include login, registration, examination, and administration. Among them, examination and administration are the core functional requirements of the system, and they contain many features, such as establishment of test database, random selection of questions, online answering management by candidates, control over the end of the examination, and several rounds of testing feedback. The structural chart for the system is presented in Figure 1.

As shown above, the $\mathrm{B} / \mathrm{S}$ architecture of the assessment system is built around the network system of the local area network (LAN)/Internet. In specific test management, the system can offer online curriculum testing in the form of campus LAN, provide distance education assessment, and achieve multivariate functions via the Internet.

\section{B. Analysis of the Development Technologies}

The development of the system originates from ASP.NET and uses SQL Server 2005 as data. Cascading Style Sheets and PHP are applied in its programming. Among these development technologies, the core is ASP.NET, a web development model launched by Microsoft to provide users with new server architecture con-

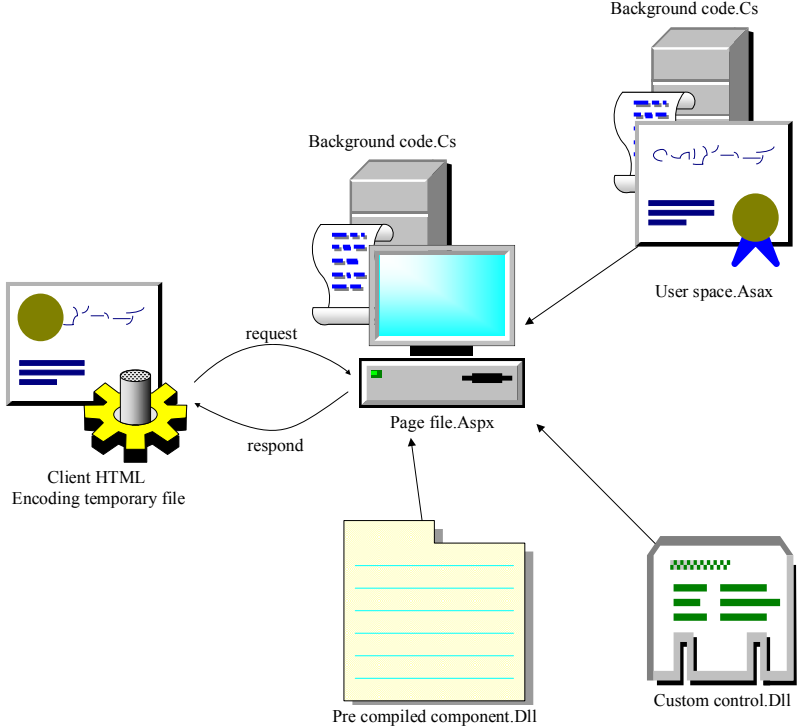

Figure 2. Static structure framework of ASP.NET

trol. This model has six objects, namely, Application, Session, ViewState, Request, Response, and Server. In practical construction, the most important feature of ASP.NET is the static structure mode of the program. This mode can greatly enhance the stability of the developed system and the rationality of the structure. Figure 2 shows the static structure framework of ASP.NET.

In the static structure framework of ASP.NET, multiple page instructions can be generated through the establishment of codes, controls, and temporary files to form a complete front-end interface. Compared with ASP, ASP.NET is more secure, has richer web controls, and can support handling more incidents over the same period not only to enhance the convenience of application development but also to greatly improve the efficiency of system operation.

\section{Design Of The Student Assessment System}

\section{A. Design of the Login Module}

The login module of the system is the homepage of the entire teaching assessment system. The specific design requires a combination with the functional design of the system. The login module is designed with two sub-modules, namely, student login module and teacher login module, to meet the requirement of using the system in assessing financial management. The login module design of the system is illustrated in Figure 3.

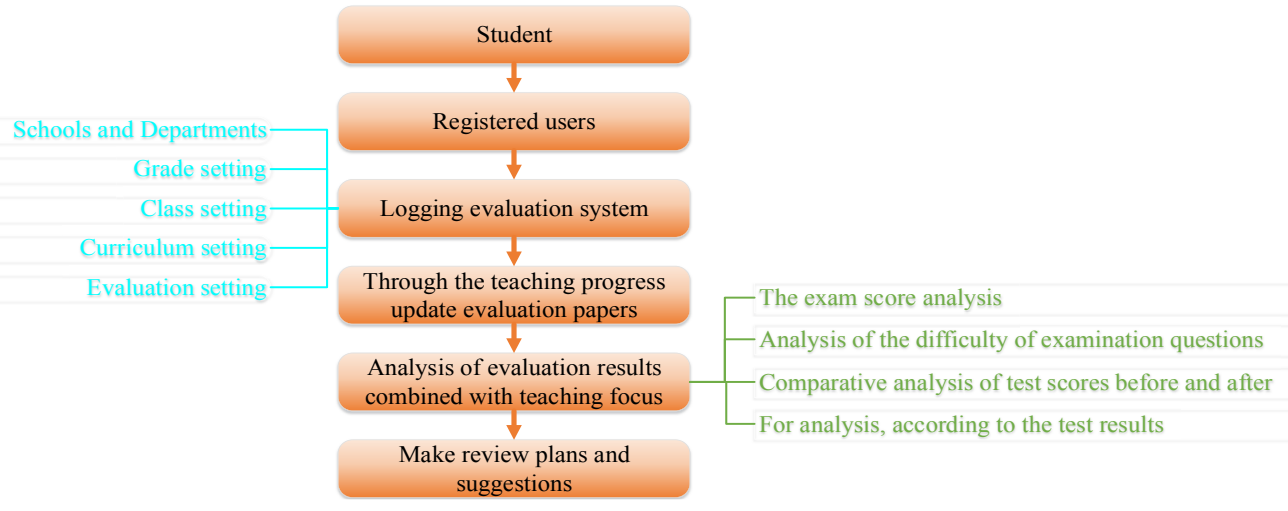

Figure 3. Login module design of the system 
As illustrated in Figure 3, in this part of the design, ASP.NET should be applied to develop two login interfaces with different login permissions, namely, login permission for teachers (administrators) and login permission for students (users). When logging on the system, both teachers and students need to enter the appropriate username and password.

The setting module is the core module of the assessment system for login setting, assessment setting, permission setting, and other operations. According to the analysis of the $\mathrm{B} / \mathrm{S}$ architecture, the module should belong to the web server layer of the system and to the data service layer, i.e., the business logic implementation layer, which mainly completes the application functions related to system setting. When the web server receives a setup request issued by a teacher or student, it exchanges relevant data with the system database based on the request type, return the processing result to the web server, and store the data processed in the database to finish the setting of the related functions of the system.

The system-setting module contains several parts, such as college, grade, class, curriculum, and assessment settings. Among them, college, grade, and class settings are mainly used for setting and storing the personal information of the logged-in user; curriculum setting is used to set information on the financial management course, such as teaching hours, teaching chapters, or teaching goals; and assessment setting completes the setting of online assessment information, such as assessment items, score distribution, and classification of questions. The system is substantially synchronized with existing teaching textbooks, provides unit and comprehensive assessment papers compiled by outstanding authoritative teachers, organizes participation of a wide range of users in the online assessment form, gives timely feedback of detailed and comprehensive assessment results and assessments, offers correct resolution processes, and guides students to pursue improvement and optimization of their learning methods.

\section{B. Design of the Assessment Administration Module}

The assessment administration module is the most critical core module of the system. It consists of several submodules, namely, question selection platform, assessment administration platform, and assessment statistics platform. Specifically, the question selection platform is primarily employed to complete the choice of assessment questions for course assessment, and the assessment administration platform mainly completes the operation of student online testing. The composition frame of the assessment statistics platform is shown in Figure 4.

In constructing the question selection platform, the algorithm of question selection should be introduced. This system uses the maximum information content-based selection method, which selects the questions with the largest item information function according to the estimated value of the current test questions to quickly and efficiently set up online exams. In the formation process, when the difficulty is close to the current ability of the one to be tested, the prediction degree is close to 1 and the value of its item function is also high. In this way, optimal choice of online test questions for the course is achieved. When the assessment administration platform operates, it can conduct online analysis and multiple rounds of testing on the assessment papers submitted by the candidate until the

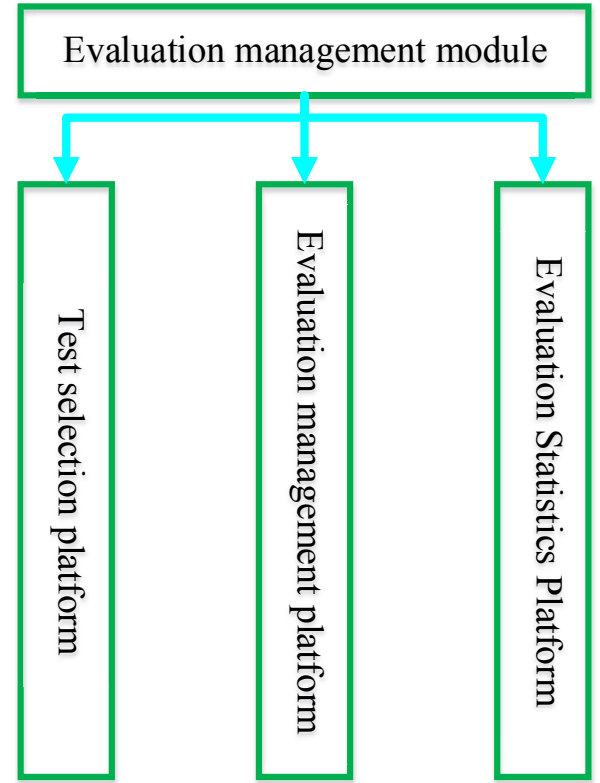

Figure 4. Functional design of the assessment administration module

error rate of the test paper is 0 , and it ultimately outputs the statistical test results in graphical form.

\section{Design of the Database}

The system uses SQL Server 2005 as the database system. Depending on the design requirements, the system database tables comprise the user information table, the assessment record table, and the question selection table. Detailed information on the system database design is presented in Tables I to III.

As shown below, the user information table mainly contains the ID, number, login name, grade, name, and other registered personal information of the user. This table also includes information on user evaluation ability, which is estimated on the basis of multiple online assessment examination results of the user. It is divided into four grades, namely, A, B, C, and D, where A indicates that the user scores in five consecutive tests are all $>85$ points; $\mathrm{B}$ means that the user scores in five consecutive tests are all $>75$ points; $C$ indicates that the user scores in five consecutive tests are all $>65$ points; and D implies that the user scores in five consecutive tests are all $<60$. The introduction of this data parameter is intended for the quantitative assessment of the evaluation level of students.

The assessment record database of the system is mainly composed of test number, question number, user answer, user is right, estimated user ability, and final user test ability. In particular, estimated user ability is updated by the system based on user testing situation after each test. By contrast, final user ability is calculated according to the results of multiple assessments and the final assessment in each semester to provide teachers with the final basis for their assessment of student achievements.

The question selection database includes some general information that can be used to measure question variables, such as question score, question difficulty, question discrimination, and user times. The above information has reference value in establishing the test database and can also be used for statistical analysis in the assessment process. 
PAPER

STUdent Assessment System for Distance EduCATION ON FinANCiAl MANAGEMENT

TABLE I.

USER INFORMATION DATABASE TABLE

\begin{tabular}{cccc}
\hline Field & Field title & Data type & Note \\
\hline User ID & User ID & Int & Non-null \\
User num & User number & nvarchar & Non-null \\
Username & Login name & nvarchar & Non-null \\
User class & User grade & nvarchar & Non-null \\
Real name & User name & nvarchar & Estimated assessment ability \\
User Latest Ability & User assessment ability & decimal & \\
\hline
\end{tabular}

TABLE II.

ASSESSMENT RECORD DATABASE TABLE

\begin{tabular}{cccc}
\hline Field & Field title & Data type & Note \\
\hline Test Num & Test number & nvarchar & Non-null \\
Test Quest Num & Question number & nvarchar & Non-null \\
User Answer & User answer & char & Non-null \\
User Is Right & User is right & bit & Non-null \\
User Ability & Estimated user ability & decimal & Updated after each test \\
User Test Ability & Final user test ability & decimal & Final estimated value generally does not change \\
\hline
\end{tabular}

TABLE III.

QUESTION SELECTION DATABASE TABLE

\begin{tabular}{|c|c|c|c|}
\hline Field & Field title & Data type & Note \\
\hline STID & Question ID & Int & 16-bit encoding \\
\hline ST Num & Question No. & nvarchar & Non-null \\
\hline ST Type & Question type & nvarchar & Non-null \\
\hline Ref Answer & Correct answer & char & Non-null \\
\hline STS core & Question score & Int & \\
\hline STB & Question difficulty & decimal & Non-null \\
\hline STA & Question discrimination & decimal & Non-null \\
\hline ST Use times & Use times & Int & Non-null \\
\hline
\end{tabular}

\section{IMPlementation Of The StUdent AssesSMENT} SYSTEM

\section{A. Implementation of the login module}

Following the design concept of this study, the system login module contains the username input and password input interface. The designed system login interface is shown in Figure 5.

\section{B. Implementation of the setting module}

As aforementioned, the system-setting module consists mainly of college, grade, class, curriculum, and assessment setting. After successful login, the user can improve personal registration information and select items of course assessment through the setting module, thus laying the groundwork for the following test. In the setting module of this system, all the contents of the course assessment setting are given. After logging on the system, the user can enjoy a welcome interface displayed with "Thank you for using the financial management academic assessment system." After the login, if the user needs to update personal registration information, he/she can select user administration setting to engage in corresponding operations. The interface for the user to improve personal information setting is presented in Figure 6.

\section{Implementation of the assessment administration module}

The assessment administration module is mainly adopted to manage student online assessment. As revealed in the design idea discussed previously, this module contains question selection, assessment statistics, and score output. The code compilation idea of the assessment administration module is similar to other modules. Overall, the joint operation of multiple modules enables the system to complete the assessment on the online distance education on financial management.

\section{ApPlication Of The StUdent Assessment SYSTEM IN TEACHING}

After the system design was completed, Classes 1 and 2, which majored in finance and were admitted in 2013 to the Changsha Environmental Protection Vocational College (Changsha, China), were selected as the objects in the study of teaching practice. These two classes were composed of 30 students each, without a significant difference $(\mathrm{P}>0.05)$ in their learning ability and academic performance in the financial management course. In teaching practice, Class 1 was selected as the experimental class, and Class 2 was treated as the control class. The traditional assessment model, namely, printed paper assessment method, was adopted for students in the control class. Their answers were assessed by the teacher to artificially obtain the statistical results. By contrast, the experimental class used the assessment system designed in this study and needed to take part in routine simulation assessment training and final examination. Eventually, the final test results of the two classes were calculated by the teacher for teaching comparison.

The experimental and control classes had significant differences in the average final exam results. In terms of the average theoretical scores, the experimental class obtained 89.2 points and the control class had 67.5 points. The average training test score of the experimental class was 95.3 points and that of the control class was 71.3 
PAPER

StUdent AsSESSMENT System For DistanCE EdUCATION ON FinANCIAL MANAGEMENT

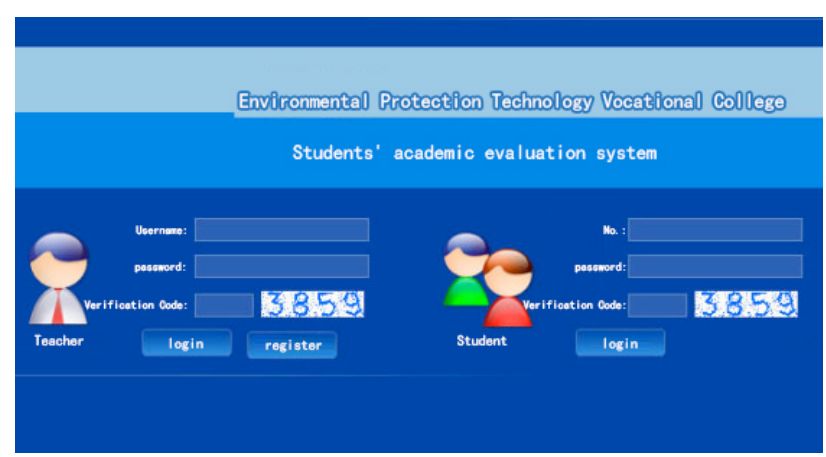

Figure 5. Interface of the system login module

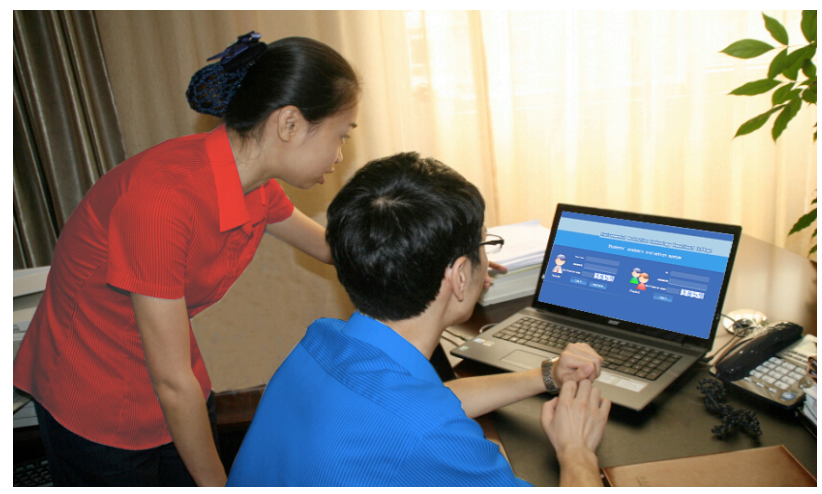

Figure 6. Login interface for user information setting

points. The result differences indicate that the introduction of the system into the course-teaching assessment of financial management played a significant role in enhancing the achievements of the students in the experimental class.

Financial management is a compulsory course for the major of finance in institutions of higher education. As the course is the core content of vocational qualification exams for finance students, it requires college teachers to give valid assessment of students based on theoretical teaching to enhance the ability of students to apply theories to solve practical problems in vocational qualification exams. In the traditional teaching model, teachers habitually use printed test papers to evaluate students. This type of teaching model is mature but less advanced, time consuming, and inefficient. The assessment system designed in this essay is based entirely on the computer system integration technology, comprehensively applies SQL database, high-level computer programming language, ASP.NET, and other advanced technologies, and can realize distance education and online assessment of financial management. Students only need to $\log$ on the system platform to test their own performance in a large number of exams consisting of randomly selected questions. For student performance assessment, teachers can easily and quickly finish their work only by using the assessment administration function provided by the application system. In this way, the efficiency of course examination is greatly enhanced, so that students have more time to select questions for self-testing or interoperable testing. With the help of the assessment statistics in the system, students can also detect their own problems in the assessment of learning, which is beneficial for upgrading the curriculum assessment level and improving performance in future vocational qualification exams.

A number of flaws, such as the lack of online interactivity, exist in the system design. Students are not allowed to communicate with teachers online for solving the questions they encounter in the course assessment process. Therefore, further improvement of the system functions is critical.

\section{CONCLUSION}

The rapid development of computer technology provides a new opportunity for the reform of teaching and assessment of the financial management course in colleges and universities. The curriculum assessment system designed in this study is based on the use of computer technologies and the integration of a variety of assessment functions. Its application in practical teaching confirms that the system is highly advanced and functional. The system is expected to be widely applied and promoted in future teaching of the course, to be constantly improved in practice, and to contribute to the assessment of the teaching of specialized courses, such as financial management.

\section{REFERENCES}

[1] Golechkova, T.Y., "A Comparative Evaluation of Alternative Blended Learning Models Used for Teaching Academic English (EAP/ESAP) to Students of Computer Sciences," Education, vol. 2, no. 7, pp. 311-317, July 2012. http://dx.doi.org/10.5923/j.edu. 20120207.14

[2] Rodrigues, F., \& Oliveira, P., "A system for formative assessment and monitoring of students' progress," Computers \& Education, vol. 76, pp. 30-41, July 2014. http://dx.doi.org/10.1016/j.comp edu.2014.03.001

[3] Kaklauskas, A., "Biometric and Intelligent Self-Assessment of Student Progress system," Computers \& Education, vol.55, no. 2, pp. 821-833, December 2014 http://dx.doi.org/10.1016/j.comp edu.2010.03.014

[4] Yu, N., "Research on College Students' Comprehensive Evaluation System Based on MVC Framework," Journal of Weinan Teachers College, no. 6, pp. 34-37, May 2015.

[5] Zhang, J.L., "Research on the Role of Mental Evaluation System in College Students' Academic and Career Planning," Vocational \& Technical Education Forum, no. 29, pp. 56-58, October 2011.

[6] Ku, D.T., Chang, W.C., "A design framework for a conceptual multi-dimensional learning assessment system," International Journal of Digital Content Technology \& Its Applications, vol. 6, no. 6, pp. 228-238, June 2012. http://dx.doi.org/10.4156/ jdcta.vol6.issue 6.27

[7] Sandoval, G.E., Valenzuela, P.M., Monge, M.M., Toso, P.A., Triviño, X.C., \& Wright, A.C., et al., "Analysis of a learning assessment system for pediatric internship based upon objective structured clinical examination, clinical practice observation and written examination," Jornal De Pediatria, vol. 86, no. 2, pp. 131-136, March-April 2010. http://dx.doi.org/10.1590/S002175572010000200009

[8] Wang, T.H., "Developing an assessment-centered e-Learning system for improving student learning effectiveness," Computers \& Education, vol. 73, no. 4, pp. 189-203, April 2014. http://dx.doi.org/10.1016/j.compedu.2013.12.002

[9] Shute, V.J., Hansen, E.G., Almond, R.G., "You Can't Fatten A Hog by Weighing It - Or Can You? Evaluating an Assessment for Learning System Called ACED," International Journal of Artificial Intelligence in Education, vol. 18, no. 4, pp. 289-316, January 2008.

[10] Zhang, W.M., “Application of ASP.NET2.0 Caching Technique in Dynamic Web Design," Software Guide, vol. 9, no. 12, pp. 138-139, December 2010.

\section{AUTHOR}

Ying $\mathbf{Y u}$ is a Senior Accountant of Changsha Environmental Protection College, Changsha, China. Her research interests include Financial Management and electronic examination system. (2581646830@qq.com)

Submitted 13 September 2016. Published as resubmitted by the authors 14 October 2016. 